\title{
KNOWLEDGE OF DIABETIC COMPLICATIONS IN A DIABETIC POPULATION
}

\author{
MIRZA AZIZUL HOQUE ${ }^{1}$, MD SIRAJUL ISLAM ${ }^{2}$, MD ABDUL MALEQUE KHAN ${ }^{3}$, HAM NAZMUL \\ AHASAN $^{4}$
}

\begin{abstract}
This cross-sectional, questionnaire based descriptive study was carried out to evaluate the individual knowledge of diabetic complications in the diabetic patients and also to find the association of knowledge towards educational status and other socio-demographic profiles. A total 184 patients were included in this study. In this study, we found 91 subjects (48.9\%) knew that heart disease was the most important diabetic complication, if blood glucose level wasn't controlled properly followed by cerebrovascular disease 27(14.7\%), renal disease 24(13\%) and eye diseases $9(4.9 \%)$. Unfortunately, awareness about frequency of diabetic foot disease, peripheral neurological problems, occurrence of sudden death were found in only 1(0.5\%) cases. Awarness about other complications (miscellaneous) was 12(6.5\%) and 8(4.3\%) didn't know any of the above mentioned complications. Each subject was also asked whether they were apprehensive about the dreaded diabetic complications or not. Statistical difference wasn't observed in any of the parameter (i.e., individual education, an area of residence, monthly income, occupations, family history of individual) when compared with the degree of apprehension. None of the parameters was statistically significant. Further expansion of diabetic education programs like using mass media and involving national curriculum of education can improve self-regulatory awareness of diabetic complications which may reduce the morbidity and mortality of diabetic patients.
\end{abstract}

Key words: diabetic complication, apprehension.

\section{Introduction}

Diabetes mellitus (DM) appears to be a global epidemic and increasingly a major non-communicable disease threatening both affluent and non-affluent society. ${ }^{1,2}$ More than 170 million people worldwide have diabetes, and this figure is projected to more than double by the year 2030, if the current trends allow to continue further. ${ }^{3}$

It will mostly increase in South Asia where India has been declared as the capital of diabetic world ${ }^{4}$. In 2007, a United Nations (UN) resolution was adopted to mark diabetes mellitus as a significance global public health issue. ${ }^{4}$

International Diabetes Federation (IDF) estimated and forecasted that 3.8 million or $4.8 \%$ of people living in
Bangladesh would be affected by diabetes mellitus by the year 2007 and the number is expected to be 7.4 million or $6.1 \%$ of the population by the year $2025 .{ }^{5}$ This explosion in diabetes prevalence will place Bangladesh among the top ten countries in terms of the number of people living with diabetes in 2025. At that time, $80 \%$ of all diabetes cases will be the burden in the low and middle socioeconomic countries than affluent society. ${ }^{6}$

Estimated cost of diagnosis in medical examination and lost productivity total $\$ 174$ billion in the U.S. in 2007. ${ }^{7}$ As the disease has got increased incidence and prevalence globally and mostly in the under developed countries therefore increased economic burden will posed for the problem as well as for its complications. Since diabetes mellitus is a life-long problem; the

1. Associate Professor, Department of Endocrinology, Dhaka Medical College, Dhaka.

2. Assistant Professor, Department of Medicine, Khulna Medical College, Dhaka.

3. Assistant Professor, Department of Ophthalmology, Khulna Medical College, Dhaka.

4. Professor \& Head, Department of Medicine, Dhaka Medical College \& Hospital, Dhaka

Correspondence : Dr. Mirza Azizul Hoque. Associate Professor, Department of Endocrinology, Dhaka Medical College, Dhaka, E-mail: mirza1962@yahoo.com 
quality of individual life can be improved if managed properly. Thus training of the individual is an integral part for self-management of diabetes. Optimum management of the problem requires an individual to be aware of the nature and consequence of the disease, its risk factors, dimensions of treatment and its complications. ${ }^{8,9}$

\section{Methods}

This cross-sectional survey on 184 diabetic subjects was conducted during the period from October 2005 to December 2005 on randomly chosen diabetic outdoor patients in Khulna Diabetic Centre, Khulna, Bangladesh.

Subjects were chosen who were more than 16 years old \& who were able to understand clearly the instructions of the survey. All the subjects had answered voluntarily and confidently against the administered pre-tested questionnaires. The entire questionnaire was available in English version but interviewed carefully with the proper translation of the official language of Bangladesh (Bengali).

The questions were aimed to assess how they came to know the diabetic complications and what were those complications? They were also asked regarding the most serious of complication of diabetes mellitus and whether they were really apprehensive or not of the problem. If the individual was found deeply apprehensive, the answer was recorded as "yes", if the individual never felt any apprehension; the answer was recorded as "no" and felt apprehension only when some body reminded him during the everyday activities. Apart from such questions, a number of answers were also gathered to compare the degree of apprehension with their demographic profiles. The whole survey was carried out in the presence of at least two of the authors. We used SPSS software Version 12 for entry and analysis of data. Chi square test was done to compare the variables.

\section{Results:}

A total of 184 individuals were surveyed. Mean $( \pm$ SD) age of the patients was $45.29( \pm 10.89)$ years. Mean $( \pm \mathrm{SD})$ duration of $\mathrm{DM}$ of the patients was $6.99( \pm 5.49)$ years. Among the subjects, female $(n=126,68.47 \%)$ preponderance was observed, Table-I higher proportion of the subjects ( $n=144,78.26 \%$ ) lived in the urban area, $122(66.3 \%)$ had attained education below Secondary School Certificate (SSC), 36(19.6\%) had SSC and Higher Secondary School Certificate (HSC) and 26(14.1\%) above HSC level (Table - II \& III). Professionally, 114 (62\%) were housewives, 27(14.7\%) service holder, $12(6.5 \%)$ business and 31(16.8) others. Individual monthly incomes of $<5000.00$ Bangladesh Taka (BDT) were 65(35.3\%), 5000.00-10000.00 were $83(45.1 \%)$ and $>10000.00$ were $36(19.6 \%$ ) (Table - IV) .

One hundred and forty-four patients (78.3\%) came to know the information of diabetic complications from the physicians of diabetic centre, 6(3.3\%) from the other physicians, $3(1.6 \%)$ from the other patients, $7(3.8 \%)$ from the near relations and others $16(8.7 \%)$ via television, radio, posters, books \& rallies. However, eight patients $(4.3 \%)$ couldn't remember the information of diabetic complications (Table-V).

\section{Table-I}

Relationship of the individual sex with the degree of apprehension for diabetic complication.

\begin{tabular}{lcccc}
\hline Sex & \multicolumn{3}{l}{$\begin{array}{l}\text { Level of apprehension for } \\
\text { diabetic complications }\end{array}$} & Total \\
\cline { 2 - 4 } & Yes & No & Occasionally & \\
\hline Male & 23 & 26 & 9 & 58 \\
Female & 62 & 43 & 21 & 126 \\
Total & 85 & 69 & 30 & 184 \\
\hline
\end{tabular}

Chi- Square value 2.029; $\mathrm{P}=0.363$, ns.

\section{Table-II}

Relationship of the individual residence with the degree of apprehension for diabetic complication.

\begin{tabular}{llccc}
\hline Area of & \multicolumn{2}{l}{ Level of apprehension } & Total \\
\cline { 2 - 3 } residence & \multicolumn{2}{c}{ for diabetic complications } & \\
\hline \multirow{3}{*}{ Rural } & Yes & No & Occasionally & \\
Urban & 21 & 14 & 5 & 40 \\
Total & 64 & 55 & 25 & 144 \\
\hline
\end{tabular}

Chi- Square value $0.979 ; \mathrm{P}=0.613$, ns 


\section{Table-III}

Relationship of the educational status with the degree of apprehension for diabetic complication.

\begin{tabular}{lcccc}
\hline \multirow{2}{*}{$\begin{array}{l}\text { Level of } \\
\text { education }\end{array}$} & \multicolumn{3}{c}{$\begin{array}{l}\text { Level of apprehension } \\
\text { for diabetic complications }\end{array}$} & Total \\
\cline { 2 - 4 } & Yes & No & Occasionally & \\
\hline Below SSC & 55 & 48 & 19 & 122 \\
SSC and HSC20 & 9 & 7 & 36 \\
Above SSC \& HSC & 10 & 12 & 426 \\
\hline Total & 85 & 69 & 30 & 184 \\
\hline
\end{tabular}

Chi- Square value $3.453 ; \mathrm{P}=0.485$, ns.

\section{Table-IV}

Relationship of the individual residence with the degree of apprehension for diabetic complication.

\begin{tabular}{lcccc}
\hline $\begin{array}{l}\text { Monthly } \\
\text { income (BDT) }\end{array}$ & \multicolumn{3}{c}{$\begin{array}{l}\text { Level of apprehension for } \\
\text { diabetic complications }\end{array}$} & Total \\
\cline { 2 - 4 } & Yes & No & Occasionally & \\
\hline$<5000$ & 27 & 25 & 13 & 65 \\
$5000-10000$ & 43 & 28 & 12 & 83 \\
More than 10000 & 15 & 16 & 5 & 36 \\
\hline Total & 85 & 69 & 30 & 184 \\
\hline
\end{tabular}

Chi-Square, $2.67 ; \mathrm{P}=0.614$, ns.

\section{Table-V}

Frequency distribution of the most serious complication of diabetes mellitus as patients came to know from different sources.

\begin{tabular}{lcc}
\hline $\begin{array}{l}\text { Complications of } \\
\text { diabetes mellitus }\end{array}$ & No of subjects Percentage \\
\hline Heart disease & 90 & 48.9 \\
Hypertension & 10 & 5.4 \\
Cerebrovascular disease & 28 & 15.2 \\
Renal disease & 24 & 13.0 \\
Diabetic foot complication & 01 & 0.5 \\
Sudden death & 01 & 0.5 \\
Neuropathy & 01 & 0.5 \\
Eye disease & 09 & 4.9 \\
Others & 12 & 6.5 \\
Not known & 08 & 4.3 \\
\hline Total & 184 & 100 \\
\hline
\end{tabular}

\section{Discussions:}

In this study, it was found that frequency distribution of the most important complication of diabetes mellitus as patients came to know from different sources, were heart disease (48.9\%), cerebrovascular disease (15.2\%), renal disease (13\%), hypertension (5.4\%), eye diseases and others by (4.3\%).There was some similarity of this study with another study where $53.5 \%$ patients reported that cardiovascular disease was a potential complication of diabetes mellitus. ${ }^{10}$ In this study, it was also shown that only $51.1 \%$ of the sample population $(\mathrm{n}=563)$ knew that diabetes is a condition which can produce life long complications if remained uncontrolled. However, another study showed that the frequency of organ damage identified in 100 diabetic patients was $91(91.1 \%)$ for eyes, heart 65(64.4\%), kidney 73(72.3), bones 34(33.7\%), feet $58(57.4 \%)$ and spine $8(7.9 \%){ }^{4}$ In our study, knowledge of cardiovascular complication mostly acquired from diabetic centre should be appreciated.

It is generally believed that male subjects aquire more knowledge for healthy life style than female. This finding is consistent with the findings of Nisar et al. conducted in Pakistan. ${ }^{11}$ Another study conducted in rural Northwest of Pakistan regarding knowledge of diabetes among patients showed that high proportion of males have better understanding of diabetes symptoms, signs and complication as compared to females and gender difference was not significant when question about suitable diet was asked for. ${ }^{12}$ Another study also showed that overall males were found more aware about diabetes mellitus, healthy diet and life style modification like practicing regular exercise. ${ }^{13}$ Another showed that the mean score of diabetic knowledge was higher in male than female. ${ }^{4}$ In our study, we didn't find any significant difference in sexes probably because of majority of the study subjects were female.

It was observed that higher education level was significantly associated with greater knowledge of diabetic symptoms, risk factors, complications and presentation ${ }^{11}$. In a study from Singapore demonstrated that diabetic education had changed the practice among diabetics towards self care. ${ }^{14}$ Another study showed that education had a significant role in diabetic awareness to keep correct blood glucose level. ${ }^{15}$ These findings are consistent with other studies. ${ }^{12,13}$ Virtually, there are no epidemiological studies in Bangladesh assessing the level of diabetic education and knowledge both in diabetic and non-diabetic population.

In a study in Pakistan, it has been shown that urban people are knowledgeable than the people residing in the rural area and they suggested the urgent need of diabetic education in the rural area. ${ }^{16}$ Of the African 
rural patient population, $52.2 \%$ had lower awareness of blood glucose compared to $47.5 \%$ of the African urban dwellers. ${ }^{17}$ In this study, there was no significant difference in apprehension of diabetic complications between rural and urban dwellers probably because diabetes targeted education was lacking in both the groups.A higher household income and the presence of a family history of diabetes were found to be positively associated with more knowledge but it is not consistent with the current study. ${ }^{18}$

\section{Conclusion:}

In this study, there was no significant association between sexes, individual's residence, level of education, individual's monthly income, occupational status compared with the level apprehension. The study subjects were mostly women (69\%), hailing from urban areas (78\%), educational level below SSC (66\%), monthly income up to 10000 BDT (\$143) in most cases $(80 \%)$ and housewives by occupation (62\%). Therefore, this study might not reflect adequately the total scenario of the area surveyed. Housewives were the main bulk of this study because of they mostly engaged with household activities having lower socioeconomic background with lower level of educational status and therefore, they had little scope to take services from the specialist corners specially in rural context of Bangladesh. To overcome this scenario mass diabetic education program is urgently needed.

\section{Acknowledgement:}

We are grateful to the study populations without whom this study would be impossible.

\section{References:}

1. Abegunde DO, Mathers CD, Adam T, et al. The burden and costs of chronic diseases in low-income and middle-income countries. Lancet 2007;370:1929-1938.

2. Hjelm K, Mufunda E, Nambozi G, et al. Preparing nurses to face the pandemic of diabetes mellitus: a literature review. J Adv Nurs 2003; 41:424-434.

3. Wild S, Roglic G, Green A, et al. Global prevalence of diabetes: estimates for the year 2000 and projections for 2030. Diabetes Care 2004;27:10471053.

4. Gulabani M, John M, Isaac R. Knowledge of diabetes, its treatment and complications amongst diabetic patients in a tertiary care hospital. Indian Journal of Community Medicine 2008; 33: 204-206.

5. Epidemiology of Diabetes Mellitus in Bangladesh. 2008. Available at: www.med.uio.no/disputaser/mo/muhammad-abdur-rahim.xml. Accessed May 15 2009.
6. International Diabetes Federation. Diabetic Association of Bangladesh supports Unite for Diabetes 2006. Available at: www.worlddia betesday.org/node/2918 Accessed May 152009.

7. American Diabetes Association: Economic costs of diabetes in the U.S. in 2007. Diabetes Care 2007;31:596-615.

8. Habib SS, Aslam M. Risk factors, knowledge and health status in diabetic patients. Saudi Med J 2003; 24(11):1219-1224.

9. Mehrotra R, Bajaj S, Kumar D, et al. Influence of education and occupation on knowledge about diabetes control. Natl Med J India 2000;13:62936296.

10. O'Sullivan EP, Bhargava A, O'Callghan M, et al. Awareness of diabetes complications in an Irish population. Available at: www.springerlink.com/ content/u272738734w836h2/ Accessed May 15 2009.

11. Nisar N, Khan IA, Qadri MH, et al. Knowledge and Risk assessment of diabetes mellitus at primary care level: A Preventive approach required combating the disease in a developing country. Pak J Med Sci 2008; 24 (5):667-672.

12. Hawthorne K, Tomlinson S. Pakistani Muslims with type 2 diabetes mellitus: effect of sex, literacy skills, known diabetic complications and place of care on diabetic knowledge, reported self-monitoring management and glycaemic control. Diabet Med 1999; 16:591-597.

13. Mehrotra R, Bajaj S, Kumar D, et al. Influence of education and occupation on knowledge about diabetes control. Natl Med J India 2000;13:293296.

14. Wee HL, Lisc HO. Public awareness of diabetes mellitus in Singapore. Singapore Med J 2002; 43(3):128-134.

15. Hoque MA, Islam MS, Nazmul Ahasan HAM et al. Achievement of awareness in a diabetic population. J Medicine 2009; 10(suppl-1):7-10.

16. Sabri AA, Qayyaum MA, Saigol NU, et al. Comparing knowledge of diabetes mellitus among rural and urban diabetics. Megill J Med 2007; 10(2): 87-89.

17. Moodley LM. An assessment of the level of knowledge about diabetes mellitus among diabetic patients in a primary healthcare setting. SA Fam Pract 2007:49(10);54-59.

18. Al Shafaee WMA, Al-Shukaili S, Rizvi SGA, et al. Knowledge and perceptions of diabetes in a semiurban Omani population. BMC Public Health 2008; 8: 249-256. 